\title{
REFERENCIAIS DE MEDIDAS DA ABNT: Instrumento para a normalização do produto de vestuário
}

MEASURES REFERENCES OF ABNT: Instrument for the standardization of clothing products

\section{Maicon Douglas Livramento Nishimura \\ Graduação em Administração Empresarial - UDESC maiconnishimura@yahoo.com.br}

\section{Eugenio Andrés Díaz Merino \\ Doutorado em Engenharia de Produção - UFSC eugenio.merino@ufsc.br \\ Leila Amaral Gontijo}

Pós-doutorado na Universidade de Lund, na Suécia leila.gontijo@ufsc.br 


\section{REFERENCIAIS DE MEDIDAS DA ABNT: Instrumento para a normalização do produto de vestuário \\ MEASURES REFERENCES OF ABNT: Instrument for the standardization of clothing products}

Maicon Douglas Livramento Nishimura, Eugenio Andrés Díaz Merino e Leila Amaral Gontijo

\section{Resumo}

Com o objetivo de padronizar as unidades de medidas do vestuário, a ABNT (Associação Brasileira de Normas e Técnicas) desenvolve pesquisas para a elaboração de referenciais de medidas nacional nos segmentos infantil, feminino e masculino. As normas de medidas infantil e masculina já estão em vigor, entretanto, ainda se trabalha para o aprimoramento de uma norma feminina. Em relação à normalização das medidas do vestuário brasileiro, buscou-se identificar a metodologia do sistema adotado para a elaboração das normas de medidas já existente e analisar como essa informação é absorvida pelo mercado de moda. A pesquisa foi pautada no levantamento bibliográfico e documental, considerando, principalmente, as normas de referenciais de medidas brasileiras e os projetos dessas normas que apresentaram pouco ou nenhum estudo antropométrico na sua metodologia. Consequentemente, percebeu-se certa fragilidade dos referenciais de medidas utilizados atualmente, porém, vislumbra-se a acuidade com os estudos que estão em desenvolvimento e com os possíveis resultados que, em breve, estarão disponíveis para análise.

Palavras- chave: Antropometria; Normalização; Vestuário

\section{Abstract}

In order to standardize the units of clothing measurements, ABNT (Brazilian Association of Technical Standards) conducts research for the development of national measures reference in children, male and female segments. The standards of child and male measures are already in place, however, still works for the improvement of a female norm. Regarding the normalization of measures of Brazilian clothing, sought to identify the system methodology adopted for the development of standards of existing measures and to analyze how this information is absorbed by the fashion market. The research was based on bibliographic and documentary survey, considering mainly the standards of Brazilian measures benchmarks and projects these rules had little or no anthropometric study in its methodology. Consequently, it was noticed certain fragility of reference measures currently used, however, the accuracy in sight with the studies that are under development and the possible outcomes that will soon be available for analysis.

Keywords: Anthropometry;

Normalization; Clothing. 


\section{INTRODUÇÃO}

Uma das dificuldades do consumidor em comprar roupas está na incompatibilidade das medidas entre as diversas empresas existentes no mercado. Não há uma conformidade entre os padrões de medidas e, ao considerar marcas estrangeiras que se instalaram no Brasil nos últimos anos, percebe-se uma realidade de gradações ainda mais divergente. Outra questão que se apresenta como empecilho para a decisão de compra é a proporção de uma peça de roupa; encontra-se uma calça que fica devidamente ajustada na cintura do consumidor, mas apertada na sua panturrilha, por exemplo.

De fato, a população brasileira possui grande variedade de biótipos, e Iida (2005) afirma que há diferenças étnicas, entre sexos e intraindividuais no estudo das medidas antropométricas do corpo humano, ou seja, nas diversas esferas de análise do corpo, existirão variáveis que individualizam as referências corporais. Esse fator dificulta bastante o trabalho do modelista e é uma problemática constante para as empresas do setor de vestuário. Contudo, há o consenso de que não é possível atender a todos com uma mesma modelagem, sendo necessárias as adaptações.

Um nicho de mercado bastante segmentado é que pode minimizar o problema de variação de medidas e o ajustamento da roupa ao corpo para o consumidor final. Além disso, qualquer fator de diferenciação é positivo para elevar uma marca ou mantê-la operante, principalmente em um mercado considerado competitivo, como é o da moda. Para tal, é necessário alinhar o projeto de um produto às necessidades e aos desejos do consumidor. Então, uma roupa com uma modelagem desenvolvida com base em parâmetros antropométricos pode mudar o grau de satisfação de quem irá comprá-la, considerando o desejo pela estética da vestimenta. (SABRÁ; CIPINIUK; MACHADO, 2012).

Evidentemente, a planificação da roupa - fase conhecida como modelagem - no processo de produção de vestuário é muito importante para a sua criação, justamente porque é quando são extraídas as partes componentes do produto final, o desenho técnico, além de outras especificações, como a ficha técnica com o passo a passo para a execução da peça. 
Quanto ao traçado da modelagem, faz-se necessário o conhecimento das medidas corporais, através da aferição com uma fita métrica; mas, no caso de uma grande confecção, a medida padrão a ser utilizada torna-se uma questão complexa. De acordo com Silveira (2008), a confecção dos moldes só oferecerá qualidade ergonômica por meio de medidas extraídas com base em estudos antropométricos focados no público-alvo do segmento de vestuário desejado.

A fim de minimizar essa questão e trazer conhecimento estatístico para a área de moda, órgãos normalizadores como a ISO (International Organization for Standardization) e a ABNT (Associação Brasileira de Normas e Técnicas) realizaram estudos que apresentam como proposta o fornecimento de medidas, baseando-se na média populacional.

No Brasil, há uma norma para o vestuário infantil e outra para o masculino que estão em vigor, bem como outros dois referenciais de medidas propostos pela ABNT, sendo que um deles abrange o corpo feminino. Contudo, trabalha-se para reformular essa norma, a exemplo do SENAI - CETIQT (Serviço Nacional de Aprendizagem Industrial - Centro de Tecnologia da Indústria Química e Têxtil), que desenvolve um trabalho que visa a oferecer uma tabela de medidas mais precisa e dentro da realidade brasileira.

E para aumentar a competitividade e diferenciação de mercado, ressalta-se a necessidade de desenvolver o conhecimento científico a partir das medidas do corpo humano, para que o mercado possa oferecer produtos com qualidade e aferidos de acordo com as normas que visam à normalização das informações sobre o consumidor (SILVEIRA, 2008).

Ao serem consideradas as dificuldades recorrentes no setor do vestuário quanto ao atendimento prestado a seus consumidores, faltando-lhes uniformidade nas medidas por parte de diversas empresas, bem como os problemas de modelagens ocasionados por desconhecimento das medidas dos brasileiros, destaca-se a importância da análise dessas problemáticas.

Dado o exposto, buscou-se identificar a metodologia do sistema adotado para a elaboração das normas de medidas do vestuário existentes no Brasil e caracterizar como essa informação é absorvida pelo mercado, por meio dos relatórios fornecidos pela instituição normalizadora e trabalhos desenvolvidos com a mesma temática. 
Para propor o aprofundamento em relação à identificação de uma metodologia e uma caraterização de mercado, foi utilizada, como embasamento científico, a metodologia de Gil (2009). Com o intuito de responder aos objetivos, houve uma pesquisa realizada em duas etapas: levantamento bibliográfico e levantamento documental. Na primeira etapa, foram consultados materiais para elucidar a temática; e, na segunda, houve a consulta das normas de referenciais de medidas do vestuário da $\mathrm{ABNT}$, assim como dos projetos da norma e de um boletim informativo, da mesma instituição, a fim de identificar como são desenvolvidas as medidas propostas e como elas são aplicadas ao mercado.

\section{ERGONOMIA, ANTROPOMETRIA E A RELAÇÃO COM O VESTUÁRIO}

A ergonomia estuda a relação do homem com o trabalho, e o vestuário faz parte desse contexto ao proteger o corpo humano no momento em que exerce uma atividade. Dessa forma, a moda se torna objeto de estudo da ergonomia, pelo fato de o vestuário compor a relação entre homem e trabalho.

Iida (2005) define ergonomia como uma relação ampla na adaptação do trabalho ao homem, ou seja, para analisar a interação do trabalho e do indivíduo, consideram-se fatores que vão além do ambiente físico. Os aspectos cognitivos e organizacionais, por exemplo, também são de interesse nessa análise, e, para o autor, a ergonomia tem seu início após a Segunda Guerra Mundial, época em que havia o trabalho de profissionais envolvidos em pesquisas militares, devido à necessidade de novas tecnologias.

Segundo a IEA - International Ergonomics Association - (2008, p.03), “ergonomia (ou Fatores Humanos) é a disciplina científica que trata da compreensão das interações entre os seres humanos e outros elementos de um sistema". A definição internacional de Ergonomia ainda divide a disciplina em três competências: ergonomia física, ergonomia cognitiva e ergonomia organizacional. A ergonomia física relaciona características referentes ao corpo e ao trabalho; a ergonomia cognitiva aborda aspectos mentais ao trabalho; e a ergonomia organizacional visualiza o sistema em que o trabalho é desenvolvido.

Com uma definição voltada para o produto, Silveira (2008) sustenta que a ergonomia se baseia na análise de critérios, cujos quais possibilitam a adaptação do 
ambiente e do produto ao indivíduo, e que, para atingir esse objetivo, adota fundamentos que preservam a vida humana nos quesitos saúde, segurança, conforto e satisfação.

Nesse contexto, de preservação do corpo, a roupa assume um de seus papéis, o de proteção. De acordo com Bezerra e Martins (2013), o vestuário faz uso de estudos ergonômicos para contribuir na adequação da roupa ao usuário em seus requisitos de conforto térmico, segurança, dinamismo e higiene, por exemplo, e a não conformidade com esses quesitos pode acarretar prejuízo ao consumidor.

Para que o produto de moda atenda aos aspectos ergonômicos, todo seu desenvolvimento deve atentar para requisitos de usabilidade, principalmente, na etapa de modelagem, já que é nessa fase em que ocorre a materialização da ideia da criação por meio do desenvolvimento de moldes que permitirão a reprodução em escala industrial (MENEZES E SPAINE, 2010).

A aplicação de medidas antropométricas no desenvolvimento do produto de moda deve estar focada no público-alvo de uma empresa. É fundamental, então, que se tenha essa informação no início do projeto, na concepção, a fim de conhecer o usuário para o qual se projeta para atender as suas características e necessidades (MENEZES E SPAINE, 2010).

Segundo Iida (2005, p.97), “a antropometria trata das medidas físicas do corpo humano", sendo de grande interesse para a moda e servindo como um dos instrumentos que a ergonomia utiliza para analisar a relação trabalho e homem. Atualmente possui enfoque multidisciplinar, porque o conhecimento do corpo humano é de interesse de diversas áreas, caracterizando-se pelo dimensionamento do corpo humano e aplicação dessas medidas (SILVEIRA, 2008).

Apesar de a conceituação ser moderna, o estudo da antropometria pode ser observado em períodos anteriores ao moderno, uma vez que diversos profissionais se preocuparam em definir medidas corporais no decorrer da história. Todavia, Silveira (2008) ressalta que foi somente a partir da década de 1940 que houve o interesse nos estudos antropométricos pelo impulso decorrente da indústria, que tinha como finalidade reduzir custos por meio da massificação de itens de vestuários e outros produtos que precisavam se adequar em relação às medidas da população. 
Dessa forma, expõe a autora que, para atender às exigências de mercado, o produto de vestuário precisa ser pensado para o consumidor, a fim de que possam ser aplicados, com qualidade, os critérios ergonômicos na confecção da roupa.

A criação de uma peça de vestuário dentro de aspectos da usabilidade precisa levar em consideração que o corpo sofre diversas modificações no decorrer da vida. Iida (2005) revela que a proporção da cabeça de um recém-nascido é de 3,8 vezes do seu corpo, enquanto que, na vida adulta, essa proporção é de 7,5 aproximadamente. Com a aproximação da velhice, o corpo sofre ainda alterações provocadas pela gradativa perda de forças e mobilidade.

A proporção da cabeça é referência fundamental no desenho de moda, porque é a partir dessa medida que se tem dimensão do corpo, conforme Maffei e Menezes (2009). Para as mesmas autoras, a imprecisão da medida utilizada, da cabeça, afeta as demais etapas do processo produtivo de moda, por permitir a interpretação da falta de padronização das medidas.

Assim, as medidas e a compreensão de movimentos são essenciais nas etapas de produção do vestuário de moda. São medidas apuradas, proporções adequadas e um traçado harmônico que definem o caimento da roupa e conferem aspectos ergonômicos a ela, além de que um produto adaptado ao consumidor permite a quem produz diferenciar-se no mercado (MENEZES E SPAINE, 2010).

Projetos de design possuem suporte na antropometria para a resolução de problemas, com o intuito de fornecer diferenciação ao produto no mercado (PIRES, 2014). Nesse sentido, ao considerar o vestuário como produto de uma metodologia de design, é possível agregar valor por meio de medidas antropométricas do usuário a que se destina a criação.

\section{METODOLOGIAS PARA O DESENVOLVIMENTO DE REFERENCIAIS DE MEDIDAS DO VESTUÁRIO NO BRASIL}

Devido à dificuldade em disponibilizar ao consumidor um produto de qualidade, principalmente em uma produção com escala industrial, países como Estados Unidos, Alemanha e França iniciaram o século XX desenvolvendo grandes pesquisas com o objetivo de propor uma tabela de medidas do corpo humano, segundo Yu (2014). O mesmo autor apresenta, cronologicamente, a evolução de estudos antropométricos em 
alguns países e verifica que o primeiro relatório sobre antropometria americana foi publicado em 1921. Ele também salienta a recomendação de um padrão comercial voltado para o vestuário 24 anos depois, em 1945, intitulado CS151.

Até o final dos anos 1980, Estados Unidos, Reino Unido, Dinamarca, Alemanha, França, Japão, Austrália, Suécia e China já possuíam tabelas com referenciais de medidas, e alguns desses países, inclusive, já haviam atualizado seus estudos.

Somente na década de 1970, por iniciativa do INT (Instituto Nacional de Tecnologia), iniciaram-se os primeiros estudos antropométricos no Brasil (BRANDÃO, 2015). Conforme a mesma autora, em 1977, o INT e a Coppe-UFRJ (Coordenação dos Programas de Pós-Graduação e Pesquisa de Engenharia da Universidade Federal do Rio de Janeiro), em conjunto, iniciaram um projeto intitulado "Medidas do Homem Brasileiro". Esse projeto teve diversas limitações técnicas, como equipamentos inadequados para a realização das medidas antropométricas e até a localização da sede para medição era desfavorável.

Essas dificuldades fizeram com que a pesquisa não fosse bem-sucedida, já que não havia consistência e representatividade nos dados obtidos. Contudo, as adversidades serviram como aprendizado sobre as limitações do projeto. Posteriormente, segundo Brandão (2015), na década de 1980, o INT esteve à frente de outra pesquisa voltada para a área agrícola que originou duas publicações: "Medidas para Postos de Trabalho" e "Medidas para o Vestuário". Percebeu-se, com isso, a necessidade de criar um banco de dados com as informações sobre o vestuário, para facilitar o acesso à informação.

Concomitantemente, surgiu, na ABNT, o Comitê de Têxtil e Vestuário, uma vez que a carência e desconformidade nas etiquetas das roupas que estavam no mercado eram comuns. As empresas se organizaram com o intuito de levantar dados antropométricos, porém, ao final do processo, elas não quiseram compartilhar a informação por uma questão estratégica.

A escassez de equipamentos antropométricos na década de 1970 e a falta de cooperativismo na década de 1980 retardaram o acesso às informações acerca do perfil físico do brasileiro. Por conta desses problemas, sugeriu-se a realização das medições, mas, ainda assim, eram comuns os relatos de que não havia consenso entre os 
profissionais da área da modelagem e de quais eram as posições corretas para medição. Somente após 14 anos de estudo é que foi criado um referencial de medidas para o corpo humano brasileiro, a NBR13377 (BRANDÃO, 2015).

Para suprir a dificuldade de identificação de parâmetros de medição no vestuário, com o objetivo de uniformizar as medidas antropométricas, em 2002, a ABNT disponibilizou a NBR12071. Nessa norma, podem ser verificados quais são os pontos de importância para a confecção de um produto de vestuário, identificando a posição de aferimento e considerando quatro peças de roupa como básicas: uma camisa, um vestido, uma saia e uma calça.

Entretanto, em 2004, foi disponibilizada a NBR15127 (ABNT, 2004) que trazia a maneira de como deveriam ser feitas as medidas corporais de um indivíduo. Foram definidos 54 parâmetros que serviriam de auxílio para a confecção do vestuário e para preencher hiatos existentes nas normas anteriores quanto à definição de marcações do corpo humano.

Apesar de normalizar as marcações de medição de peças de roupas básicas e desenvolver um referencial de medidas para o vestuário brasileiro, percebeu-se a fragilidade das informações fornecidas, justamente porque a NBR13377 não contemplava muitas medidas e perfis de usuários. Assim, nos anos posteriores, a ABNT desenvolveu duas outras normas em busca de um maior aprofundamento nos gêneros de vestuário.

Em um primeiro momento, normalizou-se a tabela de medidas infantil (NBR15800), e, posteriormente, a masculina (NBR16060). Vale ressaltar que o referencial de medida masculino é divido em três segmentos: normal, atlético e especial. Essa divisão aponta a percepção da ABNT para uma sociedade de alta variabilidade de medidas corporais e busca abranger um maior número de indivíduos para que a indústria possa trabalhar com esses dados, a fim atender a um maior critério de usabilidade no produto de vestuário.

Sobre as medidas dispostas na NBR13377, Sabrá, Santos e Dinis (2008) afirmam que elas não são resultado de um estudo antropométrico, e sim de um acordo entre representantes da cadeia têxtil da época em que foi desenvolvido o material. Evidentemente, a análise do projeto de proposta da norma NBR16060, conforme divulgado pela ABRAVEST (2011), não contempla a sugestão de um estudo 
antropométrico, e o seu embasamento está nas medidas utilizadas pelas pessoas envolvidas nesse projeto, ou seja, empresas, instituições de ensino e organizações do setor do vestuário.

Maria Adelina Pereira, superintendente da ABNT/CB-17, comenta no boletim informativo Na Medida Certa (2012) que a NBR 15800 contou com medições de crianças em creches e escolas. Porém, quando analisado o projeto da norma infantil (REVISTA ÉPOCA, 2011), percebeu-se que houve a fundamentação em informações obtidas por empresas, como na norma masculina.

O projeto da NBR15800 (REVISTA ÉPOCA, 2011), por sua vez, apresenta uma tabela com o nome de 53 pessoas e as instituições às quais elas estão vinculadas, e são principalmente as empresas do setor de confecção que fazem parte desse projeto, contando ainda com a participação de membros da ABNT, ABIT, ABRAVEST e da Draft Manequins Industriais.

Vale ressaltar que o modelo de manequim oferecido pela Drat Manequins Industriais é resultado da dissertação de mestrado de Elaine Radicetti, quem realizou o estudo visando à padronização de medidas. Já a NBR16060 contou com 21 participantes, sendo que todos já haviam participado da elaboração da norma infantil de 2009.

O SENAI/CETIQT, com uma proposta baseada em métodos antropométricos e de uso do avanço tecnológico, também inovou e desenvolve, há alguns anos, um projeto para a construção de um referencial de medidas feminino no País: Projeto de Estudo de Levantamento Antropométrico. A pesquisa inicialmente contou com a medição manual de 59 medidas definidas no escopo do projeto que, após a aquisição de um body scanner (equipamento que faz o escaneamento do corpo digitalmente) passou para 110 medidas (SABRÁ; SANTOS; DINIS, 2008).

Os autores apontam que, para o estudo, era necessário delimitar um modo e condições de medição, definir quais as medidas a serem exploradas, um tempo para medir e perguntas complementares a serem feitas, a fim de compor uma metodologia de maior fidedignidade. Com a mudança da forma de medição, foi indispensável treinar uma equipe para que o trabalho fosse feito de modo uniforme e em tempo estimado, sempre com o objetivo de seguir um método que oferecesse maior credibilidade à pesquisa. 
O objetivo dessa pesquisa desenvolvida pelo SENAI/CETIQT foi o de buscar mais informações e incorporá-las ao mercado do vestuário. Todavia, outros dados podem ser coletados para servir de base em outros campos de pesquisa no futuro. Desse modo, a complementação de um questionário qualitativo amplia a pesquisa e pode auxiliar na segmentação dos setores analisados, conforme apontam Sabrá, Santos e Dinis (2008) e Alves e Gruber (2011).

Nessa mesma perspectiva, Bastos et al. (2014) reiteram que a equipe do Projeto de Estudo de Levantamento Antropométrico, ao visar à amplitude da pesquisa, desenvolveu um questionário padronizado que aborda os hábitos de consumo da população brasileira, para ser aplicado junto às medições.

\section{A ABSORÇÃO DAS NORMAS PELO MERCADO}

Os estudos de referenciais de medidas recebem importância cada vez maior devido à necessidade desse tipo de informação para o mercado. A predominância do seu caráter estratégico permanece, assim como foi na década de 1980, e as empresas que atuam no setor de confecção carecem de medidas e informações sobre o consumidor para desenvolver seus produtos.

Sylvio Napoli, gerente de Infraestrutura e Tecnologia da ABIT (Associação Brasileira da Indústria Têxtil e de Confecção), estabelece que o progresso técnico se dá por meio do alinhamento entre produtor e consumidor e que normas podem agir como um meio para o alcance do objetivo (NA MEDIDA CERTA, 2012). Ele atesta ainda que, para satisfazer o mercado internacional, é necessário adequar o produto às medidas estrangeiras, assim, as normas com referenciais de medidas são fundamentais para essa adaptação.

Entretanto, pode-se perceber a não adesão das empresas às normas da ABNT. Seu caráter normalizador não pressupõe que as normas estão sendo seguidas, mas pode ajudar na conformidade do mercado, assim como ressalva o boletim informativo Na Medida Certa (2012). Ao serem analisadas as peças do vestuário infantil em comparação à norma NBR15800, verifica-se grande variação de mesmas medidas (BAZÁN et al., 2010).

Por outro lado, empresas do setor infantil que atuavam com e-commerce e que haviam adotado a NBR15800 estavam satisfeitos com o desempenho e retorno que 
essa adaptação da modelagem proporcionou, como, por exemplo, a redução de erro no momento de desenvolvimento da modelagem e consequente diminuição dos custos (NA MEDIDA CERTA, 2012).

As empresas Chicleteria e YKZ Moda Infantil são exemplos de empresas que aderiram à NBR15800, e os relatos das experiências e dos resultados estão no boletim informativo da ABNT de 2012. Além do retorno em relação à redução de erros na elaboração da modelagem e à padronização das medidas, os responsáveis pelas empresas relatam que a adequação das etiquetas das roupas, conforme sugere a ABNT, com a indicação das medidas referentes à peça, foi importante para fazer o consumidor identificar uma medida que atendesse às suas exigências e necessidades.

\section{CONCLUSÃO}

$\mathrm{O}$ aprofundamento dos estudos em ergonomia, principalmente o antropométrico, foi de grande valia para permitir a melhoria da usabilidade na massificação de diversos produtos, como os de segmento da moda. Entretanto, diante da realidade brasileira, ainda há espaços vazios de informações a serem preenchidos, e isso se deve ao atraso no estabelecimento da conformidade de padrões de medidas, à falta de instrumentos apropriados para uma medição precisa, à extensão do país e, principalmente, à miscigenação que resulta em uma variabilidade de biótipos.

A segmentação do perfil antropométrico por regiões pode minimizar as dificuldades encontradas em atender o público, como sugere Bazán et al. (2010). Assim, seria possível, em um menor espaço de tempo, aferir medidas de uma amostragem de uma população reduzida e, provavelmente, de menor variabilidade. Porém, ao se optar por esse método, é fundamental que as empresas repensem a sua abrangência, uma vez que a produção voltada para o ajustamento a um determinado mercado poderá deixar de atender a outro.

O desenvolvimento das pesquisas de referenciais de medidas corporais no Brasil foi um desafio, sobretudo, em relação ao tempo de duração. Aprendeu-se muito no processo, e hoje se trabalha para o aperfeiçoamento dos resultados.

A construção de uma norma para a definição de parâmetros de medidas foi fundamental no processo para tornar as pesquisas futuras uniformes. Entretanto, mesmo com a constatação da superintendente da ABNT/CB-17 quanto à realização de medições 
antropométricas em creches e escolas para a elaboração da NBR15800, percebe-se, pelo projeto da norma, que as informações foram obtidas de empresas, associações e profissionais do ramo.

Com base na proposta de projeto que originou as normas de vestuário da ABNT, mais especificamente a NBR15800 e NBR16060, pode-se perceber uma limitação da pesquisa por não abordar uma metodologia de medição antropométrica consistente, diferente do projeto que está em desenvolvimento pelo SENAI/CETIQT.

A sugestão de um método baseado em princípios antropométricos é interessante para se conferir maior confiabilidade à pesquisa. Além disso, a divisão do perfil masculino na NBR16060 vem atender a uma dificuldade percebida no mercado e, por esse motivo, poderia ser adotada no gênero infantil, afinal, a fase de crescimento da criança é caracterizada por várias mudanças corporais e de maneira rápida, como descreve Iida (2005).

As barreiras pela falta de informação antropométrica para o desenvolvimento do produto de moda sugerem possibilidades para o empresário, até porque a segmentação do público pode vir a agregar valor ao produto e garantir melhor retorno de capital. Assim, referenciar tipos de tamanho infantil pode desenvolver um nicho de mercado altamente lucrativo, como apresenta Duhigg (2012), no livro "O Poder do Hábito", em que pais de primeira viagem tendem a ser compradores impulsivos. Ademais, uma tabela de medidas uniforme pode potencializar o $e$ commerce, pois as pessoas passariam a ter mais segurança na hora da compra à medida que consumissem mais vezes, gerando, desse modo, um cliente fiel a uma marca.

Contudo, de acordo com o boletim informativo Na Medida Certa (2012), percebe-se a satisfação do empresário com as normas NBR15800 e NBR16060. Outro fator abordado no relatório e que abre margem para algumas reflexões é a adesão aos referenciais de medidas como fator de diferenciação. No mesmo material, Sylvio Napoli, da ABIT, comenta que, para a empresa atingir mercados internacionais, é necessária a adequação às medidas do país que se busca explorar mercado, para facilitar o processo de confecção.

Apesar de ter sido verificada uma evolução em relação aos referencias de medidas no Brasil nos últimos anos, o País ainda carece de estudos antropométricos. Isso é justificado com a variabilidade dos biótipos somada com a escassez de recursos 
para o desenvolvimento de pesquisas de maior confiabilidade. Com base nisso, sugerem-se, para estudos futuros, propostas de pesquisas antropométricas locais integradas que possam vir a criar um banco de dados e verificar, junto às empresas, como elas lidam com a dificuldade de parâmetros antropométricos.

\section{Artigo recebido em Agosto de 2016. Aprovado em Setembro de 2016 DOI:http://dx.doi.org/105965/1982615x10192016135}

\section{REFERÊNCIAS}

ALVES, Andressa Schneider; GRUBER, Crislaine. Estudo Comparativo Entre Tabelas de Medidas Femininas para Modelagem. In: COLÓQUIO DE MODA, 7º, 2011, Maringá. Anais Colóquio de Moda. 2011. Disponível em:

$<$ http://coloquiomoda.com.br/anais/anais/7-Coloquio-deModa_2011/GT13/Comunicacao-

Oral/CO_89501Estudo_Comparativo_entre_Tabelas_de_Medidas_Femininas_para_Mo delagem_.pdf>. Acesso em: 08 abr. 2016.

ASSOCIAÇÃO BRASILEIRA DE NORMAS TÉCNICAS. NBR 13377: medidas do corpo humano para vestuário - padrões referenciais. Rio de Janeiro: ABNT, 1995.

ASSOCIAÇÃO BRASILEIRA DE NORMAS TÉCNICAS. NBR 12071: artigos confeccionados para vestuário - determinação das dimensões. São Paulo: ABNT, 2002.

ASSOCIAÇÃO BRASILEIRA DE NORMAS TÉCNICAS. NBR 15127: corpo humano - definição de medidas. São Paulo: ABNT, 2004.

ASSOCIAÇÃO BRASILEIRA DE NORMAS TÉCNICAS. NBR 15800: vestuário referenciais de medidas do corpo humano - vestibilidade de roupas para bebê e infantojuvenil. São Paulo: ABNT, 2009.

ASSOCIAÇÃO BRASILEIRA DE NORMAS TÉCNICAS. NBR 16060: vestuário referenciais de medidas do corpo humano - vestibilidade para homens corpo tipo normal, atlético e especial. São Paulo: ABNT, 2012.

BASTOS, Sergio F. et al. SizeBR - O Estudo Antropomético Brasileiro. 2014.

Disponível em:

<http://arquivos.portaldaindustria.com.br/app/conteudo_18/2014/07/10/6822/SizeBR_P or.pdf?r=0.562248437169>. Acesso em: 08 abr. 2016.

BAZÁn, Aline Aristides et al. Antropometria para a confecção - dados de Cianorte e região. Gepros: Gestão da Produção, Operações e Sistemas, Bauru, v. 4, n. 5, p.6177, dez. 2010. Disponível em: < http://revista.feb.unesp.br/index.php/gepros/article/viewFile/887/382>. Acesso em: 08 abr. 2016. 
BEZERRA, Germana Maria Fonenelle; MARTINS, Suzana Barreto. Equação da ergonomia no design de vestuário: espaço do corpo, modelagem e materiais. 2013. Disponível em: <http://coloquiomoda.com.br/anais/anais/2-Coloquio-deModa_2006/artigos/107.pdf>. Acesso em: 27 out. 2016.

BRANDÃO, Júlia Coelho. Sistematizações de medidas de vestuário no Brasil: percepções e perspectivas. 2015. Dissertação (Mestrado em Têxtil e Moda) - Escola de Artes, Ciências e Humanidades, Universidade de São Paulo, São Paulo, 2015.

Disponível em: <http://www.teses.usp.br/teses/disponiveis/100/100133/tde-22062015103755/>. Acesso em: 2016-04-01.

DRAFT MANEQUINS INDUSTRIAIS. Disponível em: <http://www.draftmanequins.com.br/\#!sport/cl3g>. Acesso em: 08 abr. 2016.

DUHIGG, Charles. O Poder do Hábito. Rio de Janeiro: Objetiva, 2012. 408 p.

GIL, Antonio Carlos. Como elaborar projetos de pesquisa. 4. ed. São Paulo: Atlas, 2002. 175 p.

IIDA, Itiro. Ergonomia: projeto e produção. 2. ed. São Paulo: E. Blucher, 2005. 614 p.

INTERNATIONAL ERGONOMICS ASSOCIATION (EUA). Conselho Científico Internacional. Definição internacional de ergonomia. Ação Ergonômica: Revista Brasileira de Ergonomia, São Paulo, v. 3, n. 2, 2008. Disponível em:

<http://www.abergo.org.br/revista/index.php/ae/article/view/61/58>. Acesso em: 08 abr. 2016.

MAFFEI, Simone Thereza Alexandrino; MENEZES, Marizilda dos Santos. Antropometria no design de moda: da representação bidimensional ao uso tridimensional. Educação Gráfica, Bauru, v. 13, n. 02, p.188-199, 2009. Disponível em: 〈http://www.educacaografica.inf.br/revistas/vol-14-num-2-2009>. Acesso em: 08 abr. 2016.

MENEZES, Marizilda dos Santos; SPAINE, Patricia Aparecida de Almeida. Modelagem Plana Industrial do Vestuário: diretrizes para a indústria do vestuário e o ensino-aprendizado. Projética, Londrina, v. 1, n. 1, p.82-100, dez. 2010. Disponível em: < http://www.uel.br/revistas/uel/index.php/projetica/article/view/7737/6858 >. Acesso em: 27 out. 2016.

NA MEDIDA CERTA. São Paulo: Abnt, v. 10, mar. 2012. Disponível em: <http://www.abnt.org.br/images/boletim/Marco-2012.pdf >. Acesso em: 27 abr. 2016.

PIRES, Gisely Andressa et al. A ausência da padronização de medidas no vestuário infantil. In: Congresso Brasileiro De Pesquisa E Desenvolvimento Em Design, $11^{\circ}$, 2014, Gramado. Blucher Proceedings. São Paulo: Blucher, 2014. v. 1. Disponível em: <http://www.ufrgs.br/ped2014/trabalhos/trabalhos/946_arq2.pdf>. Acesso em: 08 abr. 2016.

PROJETO ROUPAS MASCULINAS. São Paulo: ABRAVEST. 2011. Disponível em: $<$ http://www.abravest.org.br/arquivos/projetoroupasmasculinas.pdf>. Acesso em: 08 abr. 2016. 
SABRÁ, Flávio. Inovação, estudos e pesquisas: reflexões para o universo têxtil e de confecção. São Paulo: Estação das Letras e Cores, Rio de Janeiro: SENAI/CETIQT, 2012. $3 \mathrm{v}$.

SABRÁ, Flávio Glória Caminada; SANTOS, Cristiane de Souza dos; DINIS, Patrícia Martins. Estabelecendo uma metodologia para medição do corpo humano. In: Colóquio de Moda, $4^{\circ}, 2008$, Novo Hamburgo. Anais Colóquio de Moda. 2008. Disponível em: <http://www.coloquiomoda.com.br/anais/anais/4-Coloquio-de-Moda_2008/42850.pdf>. Acesso em: 08 abr. 2016.

SILVEIRA, Icléia; SILVA, Giorgio. Antropometria e a sua aplicação na ergonomia do vestuário. In: Colóquio de Moda, 4ª 2008, Novo Hamburgo. Anais Colóquio de Moda. 2008. Disponível em: < http://coloquiomoda.com.br/anais/anais/4-Coloquio-deModa_2008/40376.pdf>. Acesso em: 08 abr. 2016.

VIDA ÚTIL: Norma. São Paulo. Revista Época. 2011. Disponível em:

<http://epoca.globo.com/edic/662/662_vidautil_norma.pdf〉. Acesso em: 08 abr. 2016.

YU, W. Human Anthropometrics and Sizing Systems. FAN, Jintu; YU, Winnie; HUNTER, Lawrance. Clothing appearance and fit: Science and technology. Cambridge, UK. The Textile Institute, 2004. 